\title{
Antiviral activity of carbohydrate-binding agents and the role of DC-SIGN in dengue virus infection
}

\author{
Marijke M.F. Alen, Suzanne J.F. Kaptein, Tine De Burghgraeve, Jan Balzarini, Johan Neyts, Dominique Schols* \\ Laboratory of Virology and Chemotherapy, Rega Institute for Medical Research, Katholieke Universiteit Leuven, Minderbroedersstraat 10, B-3000 Leuven, Belgium
}

\section{A R T I C L E I N F O}

Article history:

Received 6 October 2008

Returned to author for revision

17 November 2008

Accepted 26 January 2009

Available online 4 March 2009

\section{Keywords:}

Dengue virus

DC-SIGN

Carbohydrate-binding agents

Antiviral activity

\begin{abstract}
A B S T R A C T
Dendritic cell-specific intercellular adhesion molecule 3-grabbing non-integrin (DC-SIGN) is an important binding receptor for dengue virus (DENV) that recognizes N-glycosylation sites on the viral E-glycoprotein. DENV cannot bind nor infect the human B-cell line Raji/0. However, DENV productively infects Raji/DC-SIGN ${ }^{+}$cells that constitutively express DC-SIGN on their surface. IL-4-treated monocytes, expressing high levels of DC-SIGN, are also susceptible for DENV infection. Several carbohydrate-binding agents (CBAs), such as the plant lectins HHA, GNA (mannose-specific) and UDA (N-acetylglucosamine-specific), inhibited dosedependently the binding of DENV and subsequently viral replication in Raji/DC-SIGN ${ }^{+}$cells $\left(\mathrm{EC}_{50}\right.$ : $0.1-$ $2.2 \mu \mathrm{M})$. These CBAs were clearly more active against DENV in IL-4-treated monocytes ( $\left.\mathrm{EC}_{50}: 4-56 \mathrm{nM}\right)$. However, the CBAs were devoid of antiviral activity in DENV-susceptible Vero-B (DC-SIGN ${ }^{-}$) cells, demonstrating cell type-dependent differences in viral entry mechanisms.
\end{abstract}

(c) 2009 Elsevier Inc. All rights reserved.

\section{Introduction}

Dengue virus (DENV) is a single-stranded positive RNA virus of the Flaviviridae family that is transmitted by the Aedes aegypti mosquito in tropical and subtropical countries. Four genetically related DENV serotypes are known. The world health organization (WHO) estimates that 2.5 billion people are at risk to get infected with dengue. Every year there are 50 up to 100 million cases of DENV infections and approximately half a million patients require hospitalization. DENV infection can generate flu-like symptoms that can progress to dengue hemorrhagic fever/dengue shock syndrome (DHF/DSS) which is characterized by vascular leakage and thrombocytopenia causing 25,000 deaths each year (Halstead, 2007; Mairuhu et al., 2004). Dengue viruses expand their range due to the increasing habitat of the mosquito and international travel. Vaccine development would be imperative because dengue virus infections form an important economic burden especially in the developing countries. The only way at this moment to prevent DENV infection is eradication of the mosquito. The development of a dengue virus vaccine is difficult, because every serotype can cause DHF/DSS during a secondary infection. One serotype provides life-long immunity, but infection with a heterologous virus enhances the disease severity. This phenomenon is called antibody-dependent enhancement (ADE) and occurs often in children born to dengue-immune mothers. A tetravalent vaccine with low reactogenicity would be effective. Recently, a mouse and a Rhesus monkey model is proven to be effective to test antiviral compounds and possible vaccines (Bente

\footnotetext{
* Corresponding author. Fax: +32 16337340.

E-mail address: Dominique.Schols@rega.kuleuven.be (D. Schols).
}

et al., 2005; Blaney et al., 2005; Schul et al., 2007), however further investigation is required.

During a blood meal, the infected mosquito injects the virus in the skin where dendritic cells (DC) are the first target for DENV. Several investigators reported that DC-specific intercellular adhesion molecule 3-grabbing non-integrin (DC-SIGN) is essential in the infection and transmission process (Lozach et al., 2005; Navarro-Sanchez et al., 2003; Tassaneetrithep et al., 2003). DC-SIGN, mainly expressed on DC and alveolar macrophages, is a C-type (calcium-dependent) transmembrane receptor composed of four domains: a cytoplasmic domain, a transmembrane domain, seven to eight extracellular neck repeats and a carbohydrate recognition domain (CRD) (Geijtenbeek et al., 2000c; Mitchell et al., 2001; Soilleux et al., 2002). Recently, it has been shown that monocytes, but not $\mathrm{T}$ or $\mathrm{B}$ cells, are the principal target cells for DENV infection in human peripheral blood mononuclear cells (Kou et al., 2008). DC-SIGN has the capability to bind different pathogens, like human immunodeficiency virus (HIV) (Geijtenbeek et al., 2000b), human cytomegalovirus (HCMV) (Halary et al., 2002), hepatitis C virus (HCV) (Lai et al., 2006), Mycobacterium tuberculosis and several parasites and yeasts (van Kooyk and Geijtenbeek, 2003). By interaction of the virus with DC-SIGN, the virus hijacks the DC function to modulate the immune system and to disseminate the virus to the secondary lymphoid organs. Ligand interaction is abrogated with mannan and EGTA, indicating that recognition of carbohydrate structures by the lectin domain of DCSIGN is involved (Geijtenbeek et al., 2000b, 2000a; Pöhlmann et al., 2001). The CRD recognizes specific carbohydrate structures like highmannose N-glycans present on the HIV gp120 envelope (Curtis et al., 1992). DC-SIGN may be an important target for antiviral drugs because it plays an instrumental role during infection. Agents that 


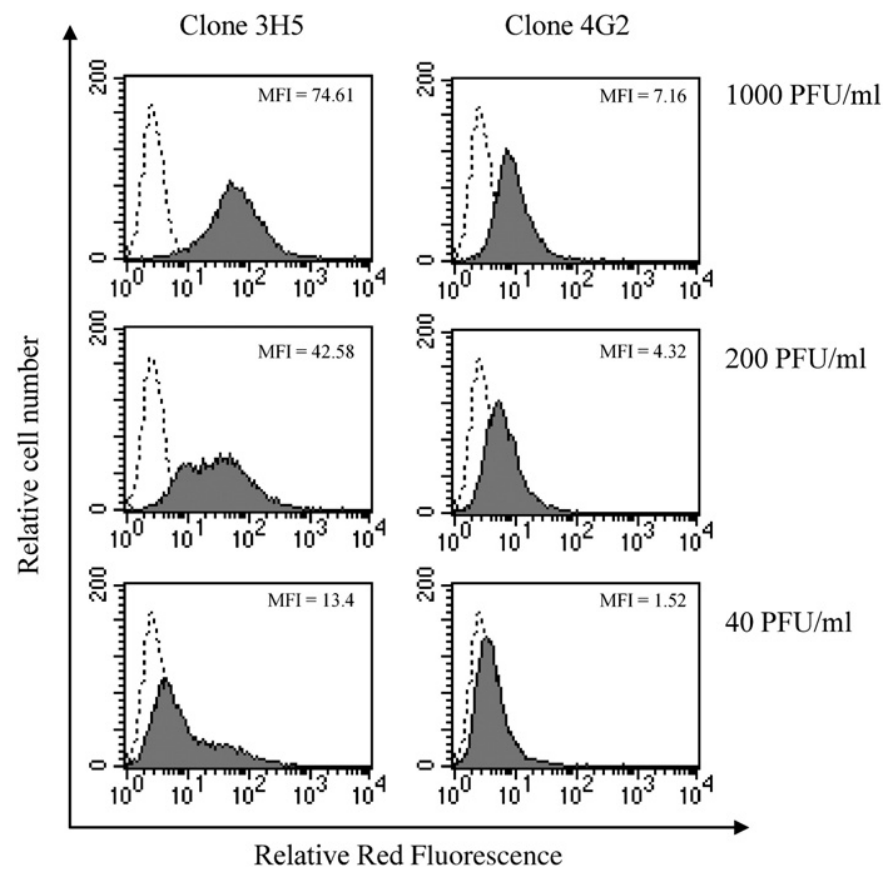

Fig. 1. Dose dependent DENV infection in Raji/DC-SIGN ${ }^{+}$cells 4 days post infection. The cells were incubated with medium alone as control (---) or with different concentrations of DENV (gray histogram) at $37{ }^{\circ} \mathrm{C}$ for 4 days. The upper panel shows the infectivity with $1000 \mathrm{PFU} / \mathrm{ml}$, the middle panel $200 \mathrm{PFU} / \mathrm{ml}$ and in the lower panel $40 \mathrm{PFU} / \mathrm{ml}$. The viral activity was quantified by flow cytometry using $5 \mu \mathrm{g} / \mathrm{ml}$ anti-DENV type 2 antibody clone 3H5 (left) or $5 \mu \mathrm{l} / \mathrm{ml}$ anti-flavivirus antibody clone 4G2 (right). $(\mathrm{MFI}=$ Mean Fluorescence of Intensity).

interact with glycoproteins, present on the virus surface, can interrupt the entry process of the virus. Indeed, carbohydrate-binding agents (CBAs) have been shown to prevent capture of HIV, simian immunodeficiency virus (SIV) and HCV to DC-SIGN ${ }^{+}$cells and prevent transmission of HIV to $\mathrm{CD}^{+}$cells in vitro (Balzarini et al., 2007; Balzarini, 2007; François et al., 2008; Turville et al., 2005). The DENV E-protein, with two potential N-linked glycosylation sites, is the only glycoprotein on the surface of DENV and is responsible for the interaction with DC-SIGN (Lozach et al., 2005).

Here, we evaluated the effect of CBAs on DENV infection using DCSIGN-transfected Raji cells. These cells can efficiently and productively be infected with DENV. The CBAs efficiently prevented DC-SIGNmediated infection in Raji/DC-SIGN ${ }^{+}$cells. When freshly-isolated monocytes were treated with IL-4 to enhance the expression of DCSIGN, they also become sensitive to DENV and the CBAs showed potent antiviral activity. The CBAs inhibited the adsorption step of DENV to the cells and we assume that CBAs interact with the E-protein of DENV as this protein has two potential N-linked glycosylation sites.

The CBAs used in our study do not show agglutination of human erythrocytes (Balzarini et al., 2004a) and they do not require uptake by the cells to induce antiviral activity. Together with the low toxicity of these CBAs and their high stability (Balzarini et al., 2004a) they should be considered as potential anti-DENV agents to be further explored in in vivo models.

\section{Results}

Optimization of dengue virus infection in Raji/DC-SIGN ${ }^{+}$cells

Previously, Gentry et al. (1982) prepared a large panel of monoclonal antibodies (mAbs) directed against the four DENV serotypes and they proved valuable for diagnostic purposes (Gentry et al., 1982; Henchal et al., 1982). Out of 22 different clones, clone 3H5 was the most specific antibody to neutralize DENV type 2 NGC at high titer. Clone 4G2 recognizes all DENV serotypes and is also used to detect DENV infection (Mondotte et al., 2007). We compared the two $\mathrm{mAb}$ clones in DENV-infected Raji/DC-SIGN ${ }^{+}$cells using different amounts of virus input. After $4 \mathrm{~h}$ incubation with the virus, the cells were washed and analyzed by flow cytometry 4 days post infection (Fig. 1). Flow cytometry data indicated that mAb 3H5 gives a higher MFI to detect dengue virus production in comparison to mAb 4G2. $1000 \mathrm{PFU} / \mathrm{ml}$ DENV represented the best (highest) infection dose and was used in the next set of experiments. Higher amounts of DENV input resulted in a saturation of the fluorescence signal and thus the number of DENV-infected cells (data not shown). To determine the time course of DENV infection, Raji/DC-SIGN ${ }^{+}$cells were collected and analyzed by flow cytometry for viral antigen expression at several days post infection (Fig. 2). In our hands, viral infection was at an optimal level to be detected by flow cytometry at day 4 post infection. These results were consistent with our other data, where DENV infection was quantified by RT-PCR reaching a maximum at 4 days post infection (data not shown).

\section{DC-SIGN expression makes cells sensitive for DENV}

To investigate the importance of DC-SIGN in the infection of DENV, we compared DC-SIGN ${ }^{+}$-transfected Raji cells to the wild-type Raji/0 cells. Parental Raji cells were not susceptible to DENV infection. This is in contrast to the $\mathrm{DC}^{-S I G N}{ }^{+}$cells which were able to become productively infected by DENV. The MFI signal representing the DENV infection was increased from $1.6 \pm 2.5$ MFI for Raji/0 cells (background) to $49.4 \pm 5.0 \mathrm{MFI}$ for Raji/DC-SIGN ${ }^{+}$cells (Fig. $3 \mathrm{~A}$ ). Preincubating Raji/DC-SIGN ${ }^{+}$cells with a specific anti-DC-SIGN mAb ( $m A b$ 120612) before the infection with DENV, resulted in inhibition of viral RNA production by $88 \% \pm 4 \%$. In contrast, IgG control isotype matched $\mathrm{mAb}$ showed no inhibitory effect (Fig. 3B). This is in accordance with the results of Tassaneetrithep et al. (2003). We then investigated the effect of mannan on the interaction between Raji/DC-SIGN ${ }^{+}$cells and DENV. We found that $2 \mathrm{mg} / \mathrm{ml}$ mannan strongly reduced the interaction of DENV with Raji/DC-SIGN ${ }^{+}$cells by $82 \pm 4.4 \%$ (Fig. $3 \mathrm{C}$ ). It is noteworthy that the $\mathrm{EC}_{50}$ for mannan is $8.2 \pm$ $5.2 \mu \mathrm{g} / \mathrm{ml}$ (Table 1 ). The astroglioma U87 wild-type cells were not sensitive to DENV infection, whereas the stably transfected U87/DC$\mathrm{SIGN}^{+}$cells were highly sensitive to DENV infection (data not shown). In addition, primary immature monocytes, which are DC-SIGN ${ }^{-}$, are

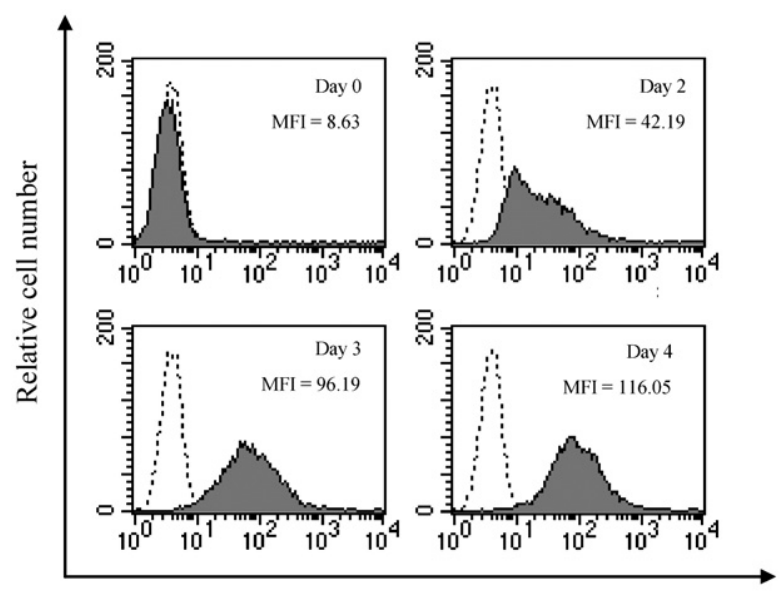

Relative Red Fluorescence

Fig. 2. Time dependent DENV infection in Raji/DC-SIGN ${ }^{+}$cells. The cells were incubated with medium alone as control (---) or with DENV (1000 PFU/ml) (gray histogram) at $37{ }^{\circ} \mathrm{C}$ and then evaluated at day 0 , at day 2, at day 3 and at day 4 . Viral infection was quantified by flow cytometry using $5 \mu \mathrm{g} / \mathrm{ml}$ anti-DENV type 2 antibody clone 3H5. (MFI = Mean Fluorescence of Intensity). 
A

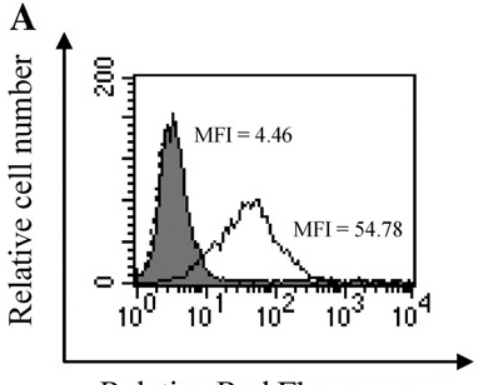

C

Relative Red Fluorescence

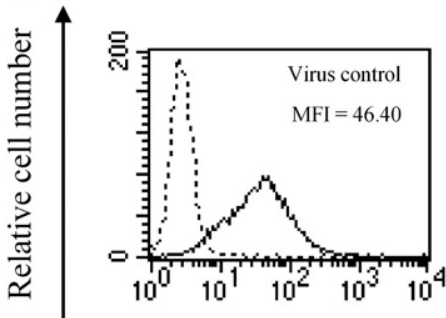

B
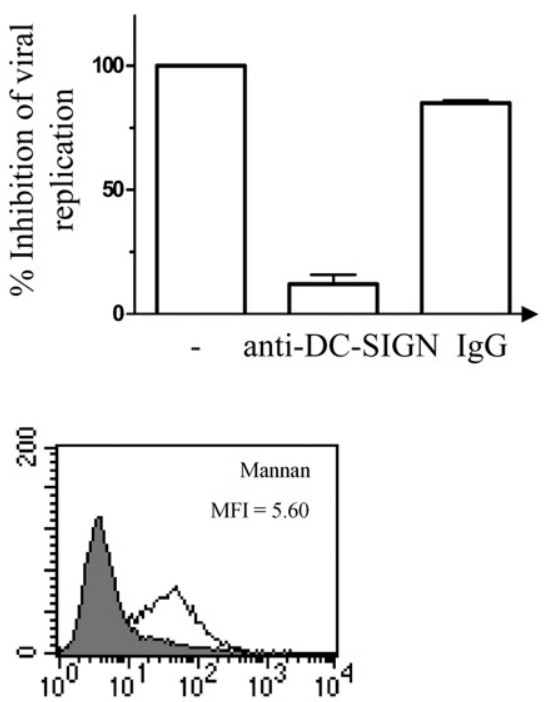

Relative Red Fluorescence

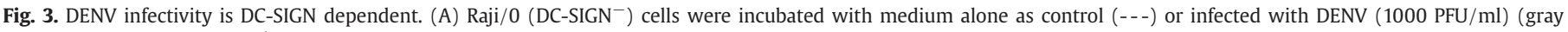

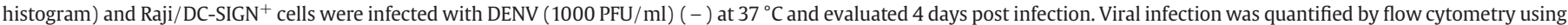

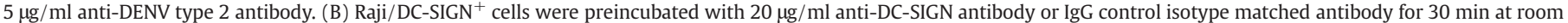

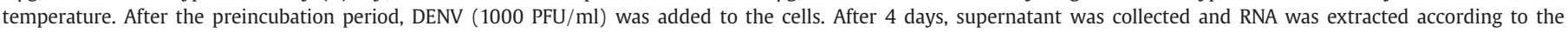

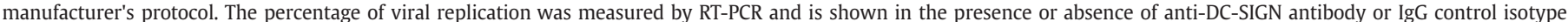

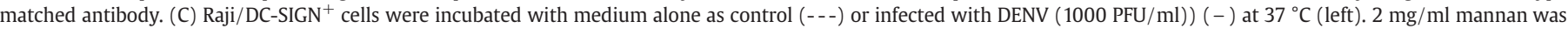

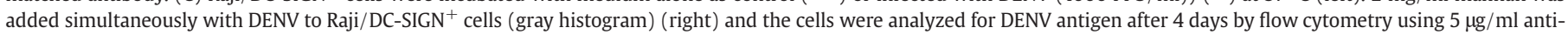

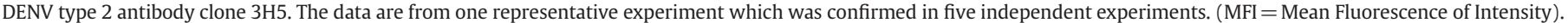

not sensitive to DENV. After a differentiation process, induced by IL-4, these IL-4-treated monocytes express high levels of DC-SIGN and become susceptible to DENV infection (monocytes: CD14 expression $=98 \% \pm 1 \%$; DC-SIGN expression $=0.3 \% \pm 0.1 \%$; IL-4-treated monocytes: CD14 expression $=30 \% \pm 12 \%$; DC-SIGN expression $=79 \% \pm 6 \%$ ). These observations lend further support to the critical role of DC-SIGN during DENV infection. Indeed, all these results indicate an important role for DC-SIGN as an entry receptor for DENV and the interaction between DC-SIGN and DENV is likely dependent on mannose-containing $\mathrm{N}$-glycans present on the DENV envelope.

Inhibitory effect of HHA, GNA, UDA and polyanions in Raji/DC-SIGN ${ }^{+}$cell cultures infected with DENV

Based on the potential of CBAs to recognize glycans present on the viral envelope, it would be interesting to investigate the antiviral potential of the CBAs against DENV infection. Raji/DC-SIGN ${ }^{+}$cells were incubated with different concentrations of the lectins HHA, GNA or UDA together with the virus for $4 \mathrm{~h}$ and the cells were harvested 4 days post infection. Expression of viral proteins on the cells was quantified by flow cytometry using the anti-E protein antibody, clone 3H5 (Fig. 4). HHA, GNA and UDA had the capability to dosedependently inhibit DENV infection. HHA and GNA were the most potent CBAs with an $\mathrm{EC}_{50}$ of $110 \pm 40 \mathrm{nM}$ and $210 \pm 110 \mathrm{nM}$, respectively. UDA was 10 - to 20 -fold less effective $\left(\mathrm{EC}_{50}: 2200 \pm\right.$ $1300 \mathrm{nM}$ ) (Table 1). The drug concentration required to cause $50 \%$ cell death $\left(\mathrm{CC}_{50}\right)$ was not obtained and is higher than the highest concentration tested.

We also evaluated several highly sulphated polyanions on DENV infection in Raji/DC-SIGN ${ }^{+}$cells. Cells were infected with DENV and different amounts of low and high molecular weight (LW and HW) DS. The cultures were analyzed 4 days later for DENV infection by flow

Table 1

Overview of the antiviral activity against DENV of several different classes of compounds evaluated in Raji/DC-SIGN ${ }^{+}$cells, VERO-B cells and IL-4-treated monocytes

\begin{tabular}{|c|c|c|c|c|c|c|c|c|}
\hline \multirow[t]{3}{*}{ Test compound } & \multicolumn{3}{|c|}{ Raji/DC-SIGN ${ }^{+}$cells } & \multicolumn{3}{|l|}{ VERO cells } & \multicolumn{2}{|c|}{ IL-4-treated monocytes } \\
\hline & $\overline{\mathrm{EC} 50^{\mathrm{a}}}$ & $\mathrm{EC}^{\mathrm{b}} \mathrm{b}^{\mathrm{b}}$ & $\mathrm{CC} 50^{\mathrm{C}}$ & $\overline{\mathrm{EC} 50^{\mathrm{a}}}$ & $\mathrm{EC} 50^{\mathrm{b}}$ & $\mathrm{CC}^{2} 0^{\mathrm{C}}$ & $\overline{\mathrm{EC} 50^{\mathrm{b}}}$ & $\mathrm{CC}^{2} 0^{\mathrm{C}}$ \\
\hline & Flow cytometry & RT-PCR & & Flow cytometry & RT-PCR & & RT-PCR & \\
\hline HHA (nM) & $110 \pm 40$ & $210 \pm 80$ & $>5,000$ & $>5,000$ & $>5,000$ & $>5,000$ & $4.4 \pm 1.2$ & $>5,000$ \\
\hline GNA (nM) & $210 \pm 110$ & $410 \pm 390$ & $>5,000$ & $>5,000$ & $>5,000$ & $>5,000$ & $3.2 \pm 1$ & $>5,000$ \\
\hline UDA (nM) & $2200 \pm 1300$ & $1830 \pm 970$ & $>20,000$ & $>20,000$ & $>20,000$ & $>20,000$ & $56 \pm 50$ & $>20,000$ \\
\hline $\mathrm{DS}(\mathrm{MW}>500,000)(\mu \mathrm{g} / \mathrm{ml})$ & $4.4 \pm 1.4$ & $7.1 \pm 0.6$ & $>100$ & $>100$ & $>100$ & $>100$ & ND & ND \\
\hline DS (MW 5000) $(\mu \mathrm{g} / \mathrm{ml})$ & $>100$ & $>100$ & $>100$ & $>100$ & $>100$ & $>100$ & ND & ND \\
\hline Mannan $(\mu \mathrm{g} / \mathrm{ml})$ & $8.2 \pm 5.2$ & $9.1 \pm 3.8$ & $>2000$ & $>2000$ & $>2000$ & $>2000$ & ND & ND \\
\hline
\end{tabular}

( $\mathrm{ND}=$ not determined, $\mathrm{DS}=$ dextran sulphate).

a $50 \%$ effective concentration, or drug concentration required to inhibit DENV infections in Raji/DC-SIGN ${ }^{+}$cells and Vero-B cells and for $50 \%$ measured by antigen expression on the cells. Values are mean \pm standard deviation of 2 to 3 separate experiments.

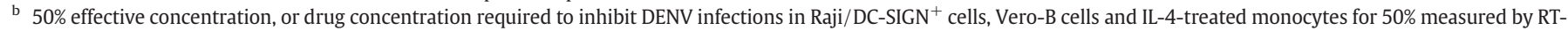
PCR in the supernatants. Values are mean \pm standard deviation of 2 to 3 separate experiments.

c $50 \%$ cell cytotoxic concentration, or drug concentration required to cause $50 \%$ cell death in Raji/DC-SIGN ${ }^{+}$cells, Vero-B cells and IL-4-treated monocytes. 


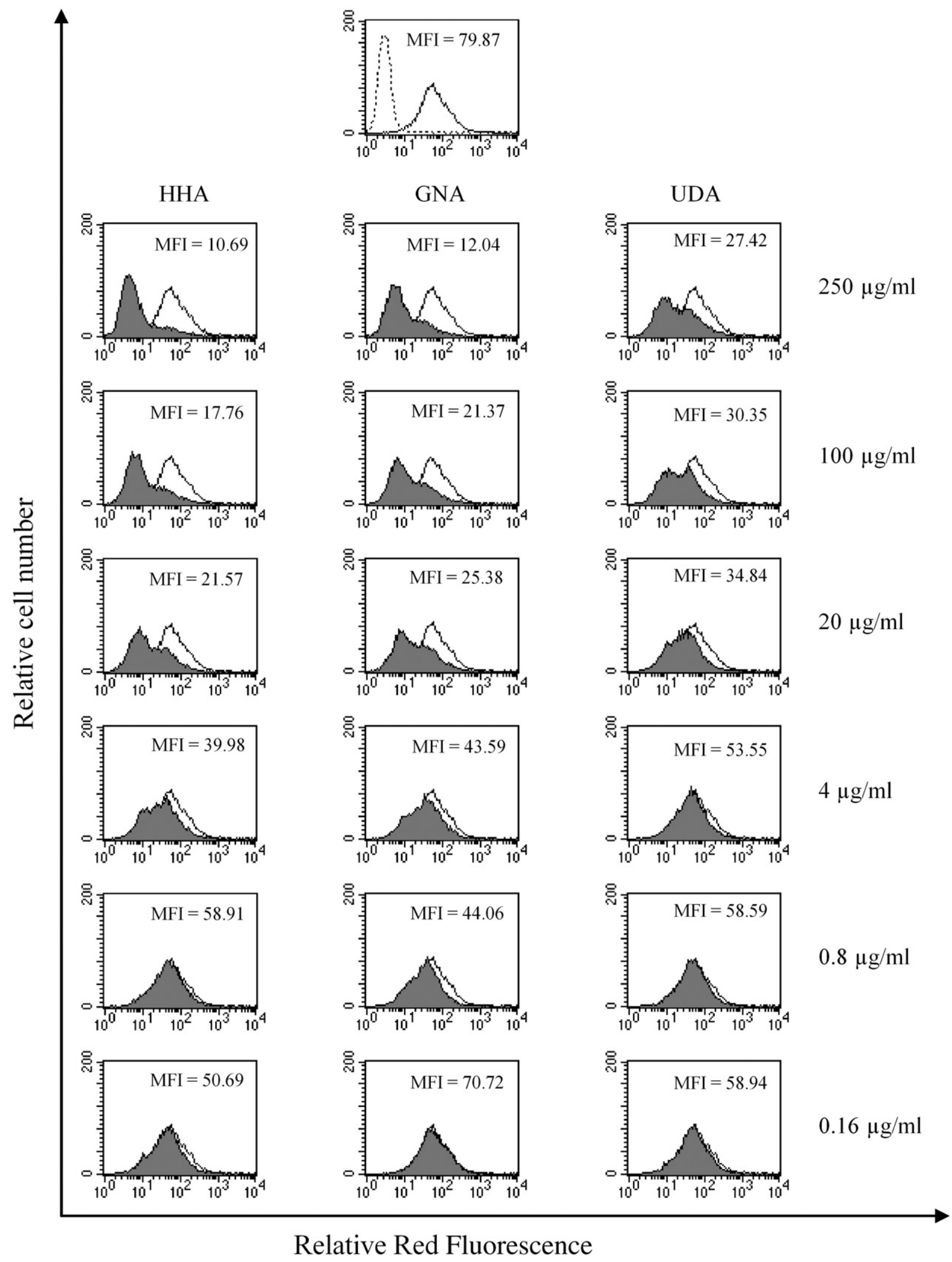

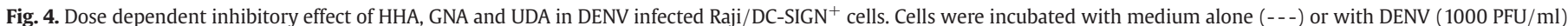

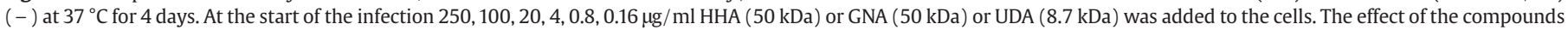

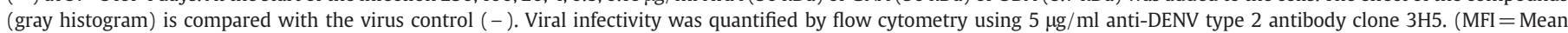
Fluorescence of Intensity.) The data shown are from one representative experiment, which was repeated three times with comparable results.

cytometry. DS HW, but not DS LW, has the capability to inhibit DENV infection in Raji/DC-SIGN ${ }^{+}$cells by $90 \pm 7.5 \%$ at a concentration of $100 \mu \mathrm{g} / \mathrm{ml}$ (Fig. 5).
The inhibitory effect of HHA, GNA, UDA and DS HW on DENV infection was further studied by quantifying the production of DENV particles in the supernatant of Raji/DC-SIGN ${ }^{+}$cells measured by RT- 
PCR (Table 1, second column). The compounds inhibited dosedependently DENV infection, although none of the compounds was able to achieve $100 \%$ inhibition at the highest concentrations tested (i.e. $100 \mu \mathrm{g} / \mathrm{ml}$ ) (Fig. 6).

To determine whether DENV infection of Raji/DC-SIGN ${ }^{+}$cells produced also infectious virus, we performed a plaque assay in Vero-B cells using DENV-infected Raji/DC-SIGN ${ }^{+}$supernatants. The Vero-B cell line is commonly used for DENV infections, because DENV induces a cytopathic effect (CPE) on Vero-B cells which makes infection visible and allows quantification of the virus titer (von Sydow et al., 2000). In contrast, Raji/DC-SIGN ${ }^{+}$cells do not show CPE after DENV infection. Raji/DC-SIGN ${ }^{+}$cells were infected in the presence or absence of various CBAs and after $4 \mathrm{~h}$ the cells were washed to remove virus and compounds. The cells were incubated for 4 days and supernatants were evaluated for infectious virus on a monolayer of Vero-B cells. The data showed that the DC-SIGN ${ }^{+}$cells produced infectious virus, indicated by the formation of plaques in Vero-B cells. The plaque formation was reduced when the initial infection had been performed in the presence of HHA, UDA, GNA or mannan (Fig. 7). Preincubation of Raji/DC-SIGN ${ }^{+}$cells with anti-DC-SIGN antibody $(10 \mu \mathrm{g} / \mathrm{ml})$ reduced the production of infectious DENV by $42 \%$ (data not shown).

Effects of CBAs and polyanions in DENV-infected Vero-B cells and potential other attachment factors for DENV

The activity of the compounds in DENV-infected Raji/DC-SIGN ${ }^{+}$ cells and Vero-B cells was compared. Vero-B cells were incubated with virus and compounds for $4 \mathrm{~h}$. After removing the excessive amount of virus, the cells were incubated for 7 days and analyzed by intracellular flow cytometry. The compounds HHA, GNA, UDA and mannan had no inhibitory activity in Vero-B cell cultures, suggesting a carbohydrateindependent binding and infection process of DENV in Vero-B cells. Surprisingly, also DS HW was not active against DENV in Vero-B cells (Fig. 8).

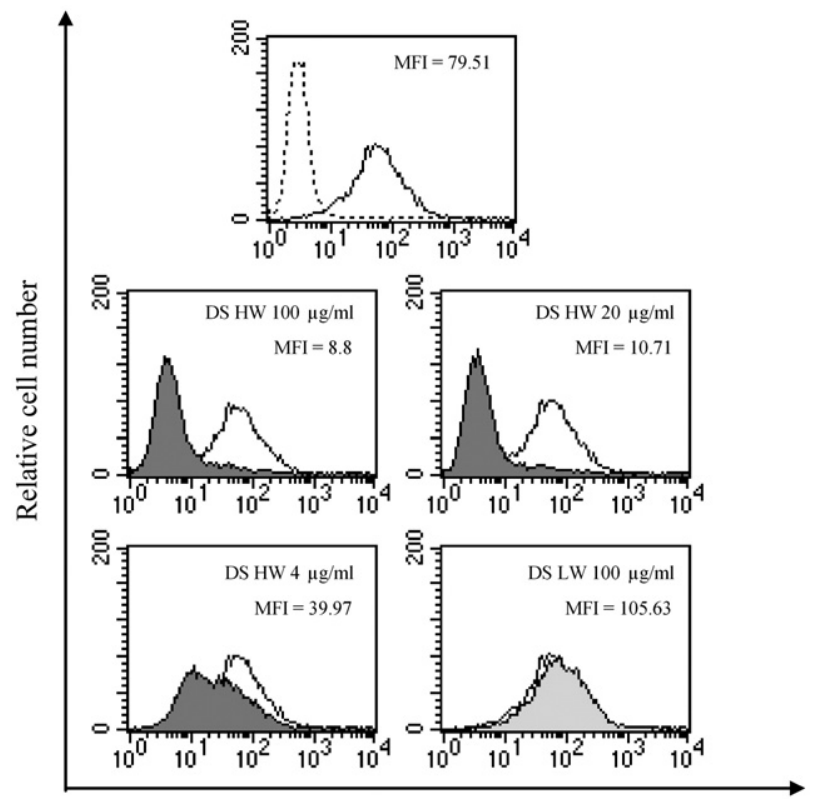

Relative Red Fluorescence

Fig. 5. Dose dependent inhibitory effect of DS HW and the effect of DS LW in DENV infected Raji/DC-SIGN ${ }^{+}$cells. (A) Cells were incubated with medium alone (---) or with DENV (1000 PFU/ml) $(-)$ at $37^{\circ} \mathrm{C}$ for 4 days. At the start of the infection 100,20 and $4 \mu \mathrm{g} / \mathrm{ml}$ DS HW was added to the cells. The effect of DS HW (dark histogram) is compared with the virus control ( - ). The effect of $100 \mu \mathrm{g} / \mathrm{ml}$ DS LW $(20 \mu \mathrm{M})$ is shown in the light histogram. Viral infectivity was quantified by flow cytometry using $5 \mu \mathrm{g} / \mathrm{ml}$ anti-DENV type 2 antibody clone 3H5. (MFI= Mean Fluorescence of Intensity).

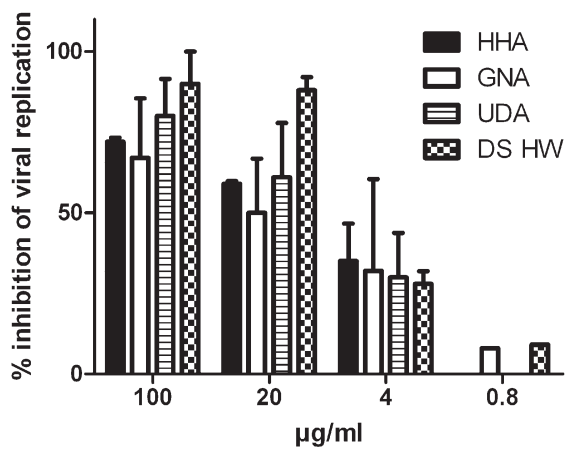

Fig. 6. Dose dependent effect of HHA, GNA and UDA in DENV infected Raji/DC-SIGN ${ }^{+}$ cells 4 days post infection measured by RT-PCR. Cells were infected with DENV (1000 PFU/ml) at $37{ }^{\circ} \mathrm{C}$ and HHA, GNA, UDA or DS HW $(100,20,4,0.8 \mu \mathrm{g} / \mathrm{ml})$ were added at the start of the infection. After 4 days, supernatant was collected and RNA was extracted. The absolute total amount of viral RNA was measured by RT-PCR. Mean \% of inhibition of the virus control \pm standard deviation of three independent experiments are shown.

Raji/DC-SIGN ${ }^{+}$and Vero-B cells strongly express the CXCR4 receptor (Balzarini et al., 2007). To study whether this receptor may be involved in the DENV infection process, we studied whether the potent CXCR4 antagonist AMD3100 prevents infection of these cells with DENV. By flow cytometry analysis we found no antiviral activity of AMD3100 (up to $60 \mu \mathrm{g} / \mathrm{ml}$ ) on DENV infection in Raji/DC-SIGN ${ }^{+}$and Vero-B cell cultures (data not shown). Also whereas the transfected U87/DC-SIGN ${ }^{+}$cell line appeared highly sensitive to DENV infection, neither wild-type U87 cells nor U87/CD4 ${ }^{+}$and U87/CD4 ${ }^{+} / \mathrm{CXCR}^{+}$ cells were infectable with DENV, indicating that the well-known HIV-1 (co)-receptors are not suitable receptors for DENV (data not shown).

\section{Effect of CBAs in IL-4-treated monocytes infected with DENV}

To determine the effect of CBAs in primary cells, we isolated monocytes from PBMCs because it has been shown that monocytes are the principal target cells for DENV infection in human PBMCs (Kou et al., 2008). After a 5 day incubation period with IL-4, $78.5 \% \pm 6 \%$ of the monocytes express DC-SIGN. We then infected the IL-4-treated cells with DENV in the presence or absence of CBAs. The lectins HHA, GNA and UDA showed potent antiviral activity with $\mathrm{EC}_{50}$ of $4.4 \mathrm{nM}$ for HHA, $3.2 \mathrm{nM}$ for GNA and $56 \mathrm{nM}$ for UDA (Table 1). The compounds showed no cytotoxic effects at the highest dose tested as determined by light microscopic evaluation as no altered morphology of the monocyte cultures was observed ( $5 \mu \mathrm{M}$ for HHA and GNA and $20 \mu \mathrm{M}$ UDA) (Table 1).

\section{Discussion}

At the site of DENV exposure, the human skin, are different subpopulations of DC that are believed to be the first target during a DENV infection. Indeed, Wu et al. (2000) demonstrated that epithelial DC of a volunteer, vaccinated with an attenuated tetravalent vaccine, stained positive for DENV glycoprotein by immunohistochemistry. DC-SIGN is a DC-specific marker that recognizes high-mannose glycans present on different pathogens. ICAM-2 and ICAM-3 are cellular ligands for DC-SIGN. Interaction of DC-SIGN with ICAM-2 results in transendothelial migration of DC (Geijtenbeek et al., 2000a) to the secondary lymphoid organs, where DC-SIGN binds ICAM-3 and initiates activation of T-cells (Geijtenbeek et al., 2000c). DC-SIGNexpressing DC are able to capture a variety of pathogens. After degradation of the pathogen, DC present the antigens to T-cells in the secondary lymphoid organs thereby activating the immune system. Thus, the first important target during an infection is DC-SIGN. Geijtenbeek et al. (2000b) demonstrated that DC-SIGN binds HIV-1 


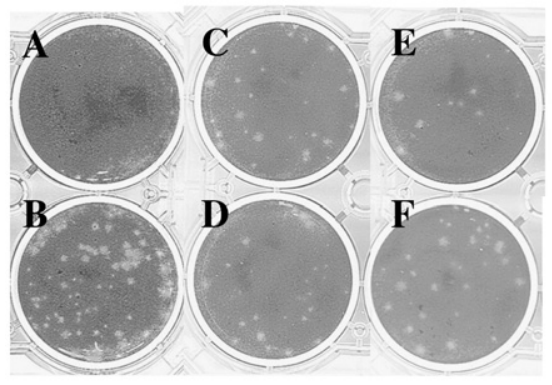

\begin{tabular}{c|c} 
Supernatant & \%CPE \\
\hline Virus Control & $100 \pm 0.0$ \\
HHA & $31.5 \pm 10.4$ \\
GNA & $46.4 \pm 8.6$ \\
UDA & $39.7 \pm 0.8$ \\
Mannan & $28.9 \pm 15.4$
\end{tabular}

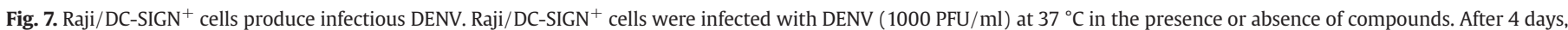

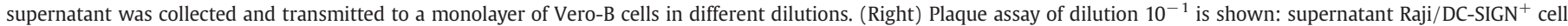

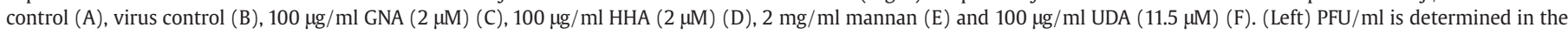
supernatant of two independent experiments and shown as percentage cytopathic effect (\% CPE) of the virus control \pm standard deviation.

envelope glycoprotein gp120 and enhances trans-infection of T-cells. Other pathogens recognized by DC-SIGN are HCMV (Halary et al., 2002), HCV (Lai et al., 2006), Mycobacterium tuberculosis and several parasites and yeasts (van Kooyk and Geijtenbeek, 2003). The crystal structure of DC-SIGN supports the high-mannose selectivity of the receptor (Feinberg et al., 2001; Guo et al., 2004). HIV-1 envelope glycoprotein gp120 contains an average of 18 to $30 \mathrm{~N}$-glycans. In contrast, DENV E-protein contains only $2 \mathrm{~N}$-glycans (Asn-67 and Asn153). Asn-67 is thought to be unique for DENV among flaviviruses and it has recently been shown that Asn-67 is responsible for the interaction of the DENV envelope with the DC-SIGN recognition domain (Mondotte et al., 2007; Pokidysheva et al., 2006).

Carbohydrate-binding agents (CBAs) and polyanions have been shown to qualify as potential microbicides to prevent HIV transmission by blocking virus entry (Balzarini and Van Damme, 2007; Pollicita et al., 2008). Other enveloped viruses including SIV (François et al., 2008), HCV (Bertaux et al., 2007) and HCMV (Balzarini et al., 1991, 1992) are found to be inhibited by several CBAs. In this study we used the DC-SIGN ${ }^{+}$Raji cell line and IL-4treated monocytes as well as the DC-SIGN ${ }^{-}$Vero-B cell line to evaluate the potential anti-DENV activity of a number of CBAs and the polyanion dextran sulphate. To measure DENV infection we used a DENV serotype 2 specific antibody, clone $3 \mathrm{H} 5$, because this clone recognizes a specific sequence in the E-protein of DENV type 2 and neutralizes the attachment of the virus (Hiramatsu et al., 1996). HHA, GNA and UDA were shown to inhibit DENV infection in Raji/ DC-SIGN $^{+}$cells with an $\mathrm{EC}_{50}$ around $110-2200 \mathrm{nM}$. Although the potency of these CBAs to inhibit DENV infection is less pronounced than their antiviral activity against $\mathrm{HIV}\left(\mathrm{EC}_{50}: 6-140 \mathrm{nM}\right.$ in T cell lines) and HCV infections (EC 50 : 3-180 nM) (Balzarini et al., 2004a; Bertaux et al., 2007), the CBAs still proved to be very efficient and non-toxic at concentrations up to $>5 \mu \mathrm{M}$ to the Raji/DC-SIGN ${ }^{+}$cells. The antiviral activity of HHA, GNA and UDA against DENV is much better in monocytes ( $\mathrm{EC}_{50}: 3-56 \mathrm{nM}$ ) and is comparable to HIV infection in $\mathrm{T}$ cell lines and also to HIV infection in monocytes $\left(\mathrm{EC}_{50}\right.$ : 38-200 nM) (Pollicita et al., 2008). In addition, a much higher dose of DENV was used to achieve a detectable infection in IL-4-treated monocytes compared to Raji/DC-SIGN ${ }^{+}$cells. This low efficiency of infection can be due to a lower expression of DC-SIGN compared to Raji/DC-SIGN ${ }^{+}$cells, but also to the characteristics (e.g. non-dividing cells) and heterogenicity of the monocyte population. The various CBAs inhibited the capture of DENV to DC-SIGN, as measured by their effect on the expression of viral antigens, and subsequently prevented the production of new virions in the supernatant. Longterm cell cultures of HIV with the mannose-specific CBAs, HHA or GNA, select for mutated viruses by deleting the N-glycans in HIV-1 gp120. This in turn makes the virus sensitive to neutralizing antibodies (Balzarini et al., 2004b, 2005). If CBAs induce this kind of mutations in the DENV envelope on the N-glycosylation sites, these sites may become a target for immune cell attack. Production of antibodies recognizing the $\mathrm{N}$-glycosylation sites could result in neutralization of all four DENV serotypes, either rendering the host immune to heterologous DENV infections, or resulting in ADE and ultimately making disease severity worse. This makes it necessary to investigate the effect of CBAs in chronic DENV-2 infections as well as in infections with other serotypes of DENV.

We found that the CBAs had no inhibitory activity against DENV infections in Vero-B cells, most likely indicating that the entry of the virus into Vero-B cells is independent of the carbohydrate-binding interaction. Screening potential antiviral agents against DENV in VeroB cells should be questioned due to the lack of important attachment factors like DC-SIGN and the lack of knowledge on the entry process of DENV in Vero-B cells. The precise mechanism of the antiviral action of CBAs in Raji/DC-SIGN ${ }^{+}$cells is not completely elucidated. Preincubation of HIV with CBAs prior to the exposure to $\mathrm{CD} 4^{+}$cells, improved

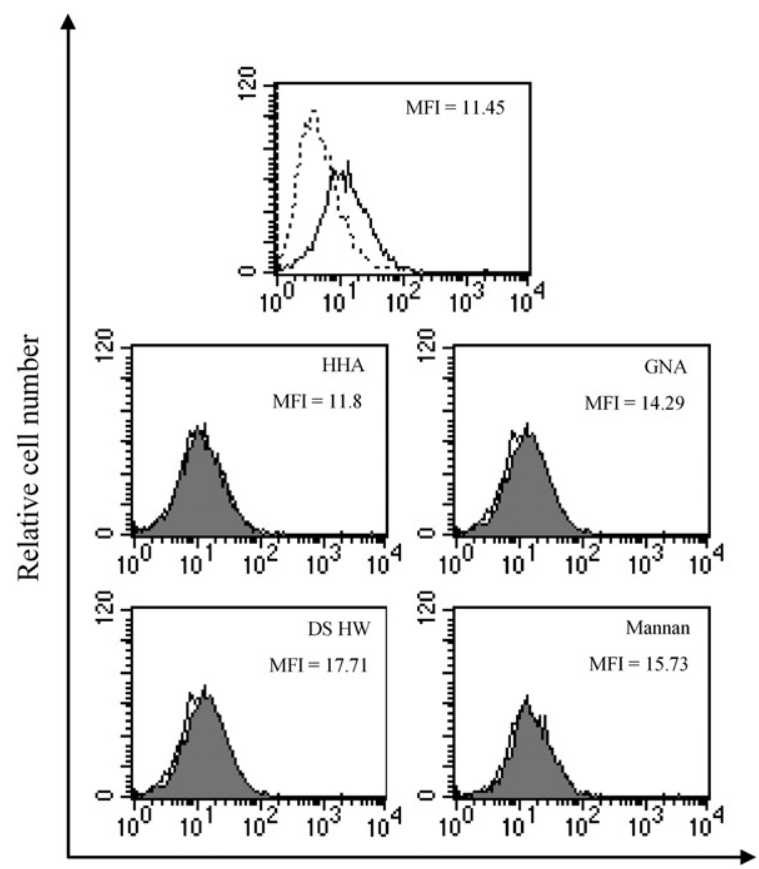

Relative Red Fluorescence

Fig. 8. Effect of HHA, GNA, DS HW and mannan in DENV infected VERO cells. Cells were incubated with medium alone (---) or with DENV $(1000 \mathrm{PFU} / \mathrm{ml})(-)$ at $37{ }^{\circ} \mathrm{C}$ for 7 days. During the infection $100 \mu \mathrm{g} / \mathrm{ml} \mathrm{HHA}(2 \mu \mathrm{M}), 100 \mu \mathrm{g} / \mathrm{ml}$ GNA $(2 \mu \mathrm{M}), 100 \mu \mathrm{g} / \mathrm{ml}$ DS HW and $2 \mathrm{mg} / \mathrm{ml}$ mannan was added to the cells. The effect of the products (gray histogram) is compared with the virus control ( - ). Cells were stained for intracellular protein E production and quantified by flow cytometry using $5 \mu \mathrm{g} / \mathrm{ml}$ anti-DENV type 2 antibody clone 3H5. (MFI= Mean Fluorescence of Intensity). 
their anti-HIV activity (Balzarini et al., 2004a). We did not observe any difference in antiviral activity of the CBAs when the CBAs were preincubated with DENV prior to exposure to Raji/DC-SIGN ${ }^{+}$cells (data not shown). This may be due to a lower affinity of the CBAs for the envelope glycans of DENV than for HIV gp120, and thus a less tight binding of the CBAs to the DENV glycans. So then we performed DENV infection of Raji/DC-SIGN ${ }^{+}$cells in the absence or presence of compounds at $4{ }^{\circ} \mathrm{C}$, and this allows no internalization of the virus into the target cell. After an incubation period of $1 \mathrm{~h}$, the cells were thoroughly washed and further cultured at $37{ }^{\circ} \mathrm{C}$ (in the absence of compounds) and 4 days later analyzed for DENV infection. The CBAs were as active and thus able to inhibit the absorption of DENV to DCSIGN. This is in accordance with our HIV and HCV data and interactions with DC-SIGN as also in these cell cultures CBAs inhibit the binding of HIV and HCV to Raji/DC-SIGN ${ }^{+}$cells (Balzarini et al., 2005, Bertaux et al., 2007).

We excluded the role of the CXCR4 receptor during DENV infection, because the CXCR4 receptor antagonist AMD3100 had no inhibitory effect on infection in the Raji/DC-SIGN ${ }^{+}$and Vero-B cell cultures, which have constitutive CXCR4 expression (Balzarini et al., 2007). To test whether CD4 could be an attachment receptor for DENV, we used U87/CD4 ${ }^{+}$cells. Although U87/DC-SIGN ${ }^{+}$cells are highly sensitive for DENV infection, U87, U87/CD4 ${ }^{+}$and $\mathrm{U} 87 / \mathrm{CD}^{+} / \mathrm{CXCR}^{+}$cells are not susceptible to DENV infection, indicating that also CD4 is not an attachment receptor for DENV. This is in accordance with the observation that monocytes, expressing DC-SIGN after a differentiation process, are the principal targets of DENV and not the low level of CD4 expression observed in monocytes (Kou et al., 2008).

Polyanions inhibit syncytia formation of $\mathrm{CD}^{+}$T-lymphocytes induced by laboratory adapted HIV-1 strains. In sharp contrast, polyanions do not have such an inhibitory activity against HIV-1 transmission from DC-SIGN ${ }^{+}$cells to T-lymphocytes (Balzarini et al., 2007). Here, we also did not observe an antiviral activity of the polyanions (i.e. DS LW) against DENV infection of Raji/DC-SIGN ${ }^{+}$cells at $100 \mu \mathrm{g} / \mathrm{ml}$. However, DS HW could block DENV infection in Raji/DC$\mathrm{SIGN}^{+}$cells. The molecular mechanism behind this observation is unclear, but it correlates with the observation that DS HW has a higher antiviral activity against HIV-1 than does DS LW (Busso and Resnick, 1990).

In conclusion, we set up an in vitro assay using DC-SIGN ${ }^{+}$Raji cells that are sensitive to DENV infection in order to evaluate potential antiviral compounds. Our data highlights the importance of DC-SIGN expression in order to make cells sensitive to DENV infection. However, the DC-SIGN-dependent infection could not be inhibited completely by a specific anti-DC-SIGN antibody and also not completely by the CBAs, suggesting still other potential entry pathways of DENV in these cells. We also demonstrated the specificity of CBAs to recognize carbohydrate binding sites on the virus envelope and, therefore, interrupting the attachment of DENV (and HIV) to DC$\mathrm{SIGN}^{+}$cells. While most compounds have their effect on a step in the replication cycle of the virus inside the cell, the CBAs exhibit a unique mechanism of antiviral action by inhibiting the virus entry process through carbohydrate binding. This study provides the first evidence that CBAs have antiviral activity against DENV.

\section{Materials and methods}

\section{Cells and viruses}

All cell cultures were maintained at $37{ }^{\circ} \mathrm{C}$ in a humidified, $\mathrm{CO}_{2^{-}}$ controlled atmosphere. African green monkey kidney cells (Vero-B cells; ATCC CCL-81) were grown in Minimum Eagle's Medium (MEM) (Invitrogen, Merelbeke, Belgium) supplemented with $10 \%$ fetal bovine serum (FBS) (Hyclone, Perbio Science, Aalst, Belgium), $2 \mathrm{mM}$ L-glutamine and $0.075 \%$ sodium bicarbonate (Invitrogen). Wild-type Raji/0 and Raji/DC-SIGN ${ }^{+}$cells were kindly provided by
Dr. L. Burleigh (Pasteur Institute, Paris, France). Raji/DC-SIGN ${ }^{+}$cells were constructed by Geijtenbeek et al. (2000b). These cell lines were cultivated in RPMI-1640 medium supplemented with 10\% FBS and $2 \mathrm{mM}$ L-glutamine. Human astroglioma U87 wild-type cells and U87 cells expressing CD4 (U87/CD4 ${ }^{+}$) were a kind gift from Dr. Dan R. Littman (Skirball Institute of Biomolecular Medicine, New York, NY, USA). U87/CD4 ${ }^{+}$cells were transfected with CXCR4 as described previously (Hatse et al., 2001). U87 cells were transfected with a DCSIGN plasmid, a kind gift from Dr. Stefan Pöhlmann (Institute for clinical and molecular virology, Erlangen, Germany) (Pöhlmann et al., 2001), using FuGENE ${ }^{\circledR} 6$ Transfection Reagent (Roche Molecular Biochemicals, Mannheim, Germany) according to the manufacturer's instructions. U87 cells were cultured in Dulbecco's modified Eagle's medium (DMEM, Invitrogen) containing 10\% FBS and 0.01 M HEPES buffer. If U87 cells express CD4, $0.2 \mu \mathrm{g} / \mathrm{ml}$ geneticin (G-418 sulfate) (Invitrogen) was added, if DC-SIGN is expressed, $50 \mu \mathrm{g} / \mathrm{ml}$ zeocin (Invitrogen) was added and if CXCR4 is expressed, $1 \mu \mathrm{g} / \mathrm{ml}$ puromycin (Sigma-Aldrich, St. Louis, MO, USA) was added to the culture medium.

Dengue virus (DENV) serotype 2 New Guinea C (NGC) strain was kindly provided by Prof. Dr. V. Deubel (Institut Pasteur, Lyon, France) and propagated in Vero-B cells. Supernatant containing virus was harvested at different time points post infection and stored at $-80^{\circ} \mathrm{C}$.

\section{Isolation and differentiation of monocytes}

Buffy coat preparations from healthy donors were obtained from the Blood Bank in Leuven, Belgium. Human peripheral blood mononuclear cells (PBMCs) were first isolated by density gradient centrifugation over Lymphoprep (Nycomed, Oslo, Norway). Monocytes were purified from PBMCs by a $2 \mathrm{~h}$ adherence step at $37{ }^{\circ} \mathrm{C}$ in $0.1 \%$ gelatin coated petridishes in culture RPMI medium. Nonadherent cells were removed by extensive washing with medium and the remaining adherent cells (monocytes) are collected. Monocytes were grown in RPMI culture medium supplemented with $25 \mathrm{ng} / \mathrm{ml} \mathrm{IL-4}$ (R\&D Systems, Abingdon, United Kingdom). After 5 days the monocytes were differentiated, because CD14 expression decreases dramatically whereas DC-SIGN expression was strongly upregulated, as analyzed by flow cytometry (our own data, Miller et al., 2008; Wu et al., 2002).

\section{Test compounds}

The mannose-specific plant lectins from Hippeastrum hybrid (HHA) (50 kDa), Galanthus nivalis (GNA) (50 kDa) and the Nacetylglucosamine-specific plant lectin from Urtica dioica (UDA) ( $8.7 \mathrm{kDa}$ ) were derived and purified from these plants as described previously (Van Damme et al., 1987, 1988, 1991). Mannan, isolated from Saccharomyces cerevisiae, and dextran sulphate (DS), (low molecular weight $5 \mathrm{kDa}$ and high molecular weight $>500 \mathrm{kDa}$ ) derived from Leuconostoc mesenteroides, were purchased from Sigma (St. Louis, MO). The bicyclam AMD3100 was obtained from Anormed (Langley, Canada). Purified DC-SIGN antibody was purchased from R\&D Systems (clone 120612,) and purified mouse IgG isotype control antibody was purchased from BD Pharmingen (clone MOPC-173, BD Biosciences, San Jose, CA).

\section{Antiviral assays}

Raji/0, Raji/DC-SIGN ${ }^{+}$, Vero-B cells and the U87 cell lines $\left(0.510^{6}\right.$ cells/well) were infected with $\operatorname{DENV}(40,200,1000 \mathrm{PFU} / \mathrm{ml})$ in the absence or presence of compound for $4 \mathrm{~h}$ at $37{ }^{\circ} \mathrm{C}$. IL-4-treated monocytes $\left(0.110^{6}\right.$ cells $\left./ \mathrm{ml}\right)$ were infected with a high multiplicity of infection (MOI) of DENV in the absence or presence of compound for $4 \mathrm{~h}$ at $37{ }^{\circ} \mathrm{C}$ and analyzed for DENV infection after different timepoints. The cells were washed twice with medium to remove excessive 
virus and incubated at $37{ }^{\circ} \mathrm{C}$ in fresh culture medium. Raji/ 0 and Raji/ DC-SIGN $^{+}$cells were analyzed for DENV infection on day 0, 2, 3 and 4 after infection. U87 cell lines were incubated for 6 days and Vero-B cells were incubated for 7 days.

The supernatant was always stored at $-80{ }^{\circ} \mathrm{C}$ for RNA-extraction and RT-PCR and the cells were used to detect DENV antigen by flow cytometry.

At the end of the culture period, the 50\% cell cytotoxicity concentration $\left(\mathrm{CC}_{50}\right)$ was determined in IL-4-treated monocytes and Vero-B cells by light microscopic evaluation for morphological changes and for Raji/DC-SIGN ${ }^{+}$cells by counting the cells in a Coulter Counter (Analis, Ghent, Belgium).

\section{RNA extraction and real time (RT)-PCR}

Total RNA was extracted from $150 \mu$ cell culture supernatant using the Nucleospin RNA Virus Kit according to the manufacturer's instructions (Macherey-Nagel, Düren, Germany). The sequences of the forward (5'-TCGGAGCCGGAGTTTACAAA-3' position 4628-4647) and reverse (5'-TCTTAACGTCCGCCATGAT-3', position 4722-4741) Taqman primers were selected from non-structural gene 3 (NS3) of DENV NGC using Primer Express software (version 2.0, Applied Biosystems, Lennik, Belgium). The probe was selected between the primers and is fluorescently labeled with 6-carboxyfluorescein (FAM) at the $5^{\prime}$ end as the reporter dye and with a quencher at the $3^{\prime}$ end. The quencher is a minor groove binder (MGB) (5'-FAMATTCCACACAATGTGGCA-MGB-3', position 4656-4674). The nucleotide sequence and position of the primers and probes were obtained from the nucleotide sequence of DENV 2 NGC (Genbank accession no. M29095) (Irie et al., 1989). One step RT-PCR was performed in a $25 \mu$ reaction mixture containing $12.5 \mu$ l One-Step Reverse Transcriptase qPCR Master Mix (Eurogentec, Seraing, Belgium), $900 \mathrm{nM}$ forward primer, $900 \mathrm{nM}$ reverse primer, $200 \mathrm{nM}$ probe and $100 \mathrm{ng}$ sample RNA. RT-PCR was performed under the following conditions: reverse transcription at $48{ }^{\circ} \mathrm{C}$ for $30 \mathrm{~min}$, initial denaturation at $95{ }^{\circ} \mathrm{C}$ for $10 \mathrm{~min}$, followed by 40 cycles of denaturation at $95{ }^{\circ} \mathrm{C}$ for $15 \mathrm{~s}$, annealing and extension at $60{ }^{\circ} \mathrm{C}$ for 1 min. RT-PCR was performed using the ABI 7500 Fast Real-Time PCR System (Applied Biosystems, Branchburg, New Jersey, USA) and data were analyzed with ABI PRISM 7500 SDS software (version 1.3.1, Applied Biosystems). Standard curves were made of dengue virus plasmid with known concentrations to calculate the absolute quantification of infection.

\section{Flow cytometry analysis}

Raji/0 and Raji/DC-SIGN ${ }^{+}$cells were infected with DENV and incubated for $0,2,3$ or 4 days. Cells were collected, washed with phosphate buffered saline (PBS) supplemented with 2\% FBS and stained with monoclonal anti-dengue virus type 2 antibody, specific to the E-glycoprotein of DENV type 2 NGC (clone 3H5, Chemicon International/Millipore, Billerica, MA) or with anti-flavivirus group antigen monoclonal antibody (clone 4G2, Chemicon International/ Millipore, Billerica, MA) (Henchal et al., 1982; Hiramatsu et al., 1996). After an incubation period of $30 \mathrm{~min}$ at room temperature, cells were washed with PBS and incubated with secondary phycoerythrinconjugated goat $\mathrm{F}\left(\mathrm{ab}^{\prime}\right)_{2}$ anti-mouse antibody ( $1 \mu \mathrm{g} / \mathrm{ml}$, Invitrogen) for 30 min. Finally the cells were washed with PBS and fixed with $1 \%$ paraformaldehyde. Vero-B cells were infected with DENV and after trypsin digestion, the cells were fixed with $2 \%$ paraformaldehyde for $10 \mathrm{~min}$ at $37^{\circ} \mathrm{C}$ and then permeabilized with $90 \%$ methanol for $30 \mathrm{~min}$ on ice. After washing the cells with PBS and $2 \%$ FBS the permeabilized cells were stained with anti-dengue virus type $2 \mathrm{mAb}$ (clone $3 \mathrm{H} 5$ ) for 30 min at room temperature. Then the cells were washed with PBS and secondary phycoerythrin-conjugated goat $\left.\mathrm{F}(\mathrm{ab})_{2}\right)_{2}$ anti-mouse antibody was added (Caltag Invitrogen, Carlsbad, CA).
As a control for unspecific background staining, Raji/0, Raji/ DC-SIGN $^{+}$and Vero-B cells were stained in parallel with secondary antibody only. Then the stained cells were washed and analyzed by flow cytometry with a FACSCalibur (BD, San Jose, CA). Data were acquired and analyzed with CellQuest software (BD). The mean fluorescence of intensity (MFI) of the background staining was subtracted from the MFI of each sample to obtain the percentage of DENV-infected cells.

\section{Viral plaque assay}

Three 10 -fold serial dilutions $\left(10^{-1}-10^{-3}\right)$ were made for each supernatant sample into 6-well plates containing a confluent monolayer of Vero-B cells. Following an incubation of $2 \mathrm{~h}$, the cells were washed 3 times with culture medium and overlaid with a solution containing 0.5\% Avicel $^{\circledR}$ (Matrosovich et al., 2006) and medium, supplemented with $2 \% \mathrm{FBS}, 2 \mathrm{mM}$ L-glutamine and $0.075 \%$ sodium bicarbonate, in a ratio $1: 1$. Avicel restricts the spread of virus in cell culture. After 1 week the cells were washed with PBS, fixed with $70 \%$ ethanol and stained with $1 \%$ methylene blue solution to visualize the plaques. Plaques were counted to determine the number of plaque forming units per milliliter supernatant $(\mathrm{PFU} / \mathrm{ml})$.

\section{Acknowledgments}

We are grateful to S. Claes, R. Provinciael, E. Fonteyn, S. Delmotte and S. Roofthooft for excellent technical assistance. This work was supported by the European Commission EMPRO No. 503558 of the 6th Frame Work Programme, FP6-2003-INCO-DEV2 DENFRAME “Innovative diagnostic tools and therapeutic approaches for dengue disease" (Contract No.: 517711), the Fonds voor Wetenschappelijk Onderzoek (FWO) Krediet nr. G-485-08, the Centers of Excellence of the K. U. Leuven (Krediet nr. EF/05/015) and the Fondation Dormeur.

\section{References}

Balzarini, J., 2007. Targeting the glycans of glycoproteins: a novel paradigm for antivira therapy. Nat. Rev., Microbiol. 5, 583-597.

Balzarini, J., Van Damme, L., 2007. Microbicide drug candidates to prevent HIV infection. Lancet 369, 787-797.

Balzarini, J., Schols, D., Neyts, J., Vandamme, E., Peumans, W., De Clercq, E., 1991. Alpha(1-3)-D-mannose-specific and alpha-(1-6)-D-mannose-specific plant lectins are markedly inhibitory to human immunodeficiency virus and cytomegalovirus infections in vitro. Antimicrob. Agents Chemother. 35, 410-416.

Balzarini, J., Neyts, J., Schols, D., Hosoya, M., Vandamme, E., Peumans, W., De Clercq, E., 1992. The mannose-specific plant lectins from Cymbidium hybrid and Epipactis helleborine and the (N-acetylglucosamine) $\mathrm{N}$-specific plant lectin from Urtica dioica are potent and selective inhibitors of human immunodeficiency virus and cytomegalovirus replication in vitro. Antivir. Res. 18, 191-207.

Balzarini, J., Hatse, S., Vermeire, K., Princen, K., Aquaro, S., Perno, C.F., De Clercq, E. Egberink, H., Vanden Mooter, G., Peumans, W., Van Damme, E., Schols, D., 2004a Mannose-specific plant lectins from the Amaryllidaceae family qualify as efficient microbicides for prevention of human immunodeficiency virus infection. Antimicrob. Agents Chemother 48, 3858-3870.

Balzarini, J., Van Laethem, K., Hatse, S., Vermeire, K., De Clercq, E.R., Peumans, W., Van Damme, E., Vandamme, A.M., Bohlmstedt, A., Schols, D., 2004b. Profile of resistance of human immunodeficiency virus to mannose-specific plant lectins. J. Virol. 78, 10617-10627.

Balzarini, J., Van Laethem, K., Hatse, S., Froeyen, M., Peumans, W., Van Damme, E., Schols, D., 2005. Carbohydrate-binding agents cause deletions of highly conserved glycosylation sites in HIV GP120 - a new therapeutic concept to hit the Achilles heel of HIV. J. Biol. Chem. 280, 41005-41014.

Balzarini, J., Van Herrewege, Y., Vermeire, K., Vanham, G., Schols, D., 2007. Carbohydrate-binding agents efficiently prevent dendritic cell-specific intercellular adhesion molecule-3-grabbing nonintegrin (DC-SIGN)-directed HIV-1 transmission to T lymphocytes. Mol. Pharmacol. 71, 3-11.

Bente, D.A., Melkus, M.W., Garcia, J.V., Rico-Hesse, R., 2005. Dengue fever in humanized NOD/SCID mice. J. Virol. 79, 13797-13799.

Bertaux, C., Daelemans, D., Meertens, L., Cormier, E.G., Reinus, J.F., Peumans, W.J. Van Damme, E.J.M., Igarashi, Y., Oki, T., Schols, D., Dragic, T., Balzarini, J., 2007. Entry of hepatitis $C$ virus and human immunodeficiency virus is selectively inhibited by carbohydrate-binding agents but not by polyanions. Virology 366, 40-50.

Blaney, J.E., Matro, J.M., Murphy, B.R., Whitehead, S.S., 2005. Recombinant, liveattenuated tetravalent dengue virus vaccine formulations induce a balanced, broad, 
and protective neutralizing antibody response against each of the four serotypes in rhesus monkeys. J. Virol. 79, 5516-5528.

Busso, M.E., Resnick, L., 1990. Anti human immunodeficiency virus effects of dextran sulfate are strain dependent and synergistic or antagonistic when dextran sulfate is given in combination with dideoxynucleosides. Antimicrob. Agents Chemother. 34 1991-1995.

Curtis, B.M., Scharnowske, S., Watson, A.J., 1992. Sequence and expression of a membrane-associated C-type lectin that exhibits CD4-independent binding of human immunodeficiency virus envelope glycoprotein gp120. Proc. Natl. Acad. Sci. U.S.A. $89,8356-8360$.

Feinberg, H., Mitchell, D.A., Drickamer, K., Weis, W.I., 2001. Structural basis for selective recognition of oligosaccharides by DC-SIGN and DC-SIGNR. Science 294, 2163-2166.

François, K.O., Auwerx, J., Schols, D., Balzarini, J., 2008. Simian immunodeficiency virus is susceptible to inhibition by carbohydrate-binding agents in a manner similar to that of HIV: implications for further preclinical drug development. Mol. Pharmacol. 74, 330-337.

Geijtenbeek, T.B.H., Krooshoop, D.J.E.B., Bleijs, D.A., van Vliet, S.J., van Duijnhoven, G.C.F., Grabovsky, V., Alon, R., Figdor, C.G., van Kooyk, Y., 2000a. DC-SIGN-ICAM-2 interaction mediates dendritic cell trafficking. Nat. Immunol. 1, 353-357.

Geijtenbeek, T.B.H., Kwon, D.S., Torensma, R., van Vliet, S.J., van Duijnhoven, G.C.F., Middel, J., Cornelissen, I.L.M.H., Nottet, H.S.L.M., KewalRamani, V.N., Littman, D.R. Figdor, C.G., van Kooyk, Y., 2000b. DC-SIGN, a dendritic cell-specific HIV-1-binding protein that enhances trans-infection of T cells. Cell 100, 587-597.

Geijtenbeek, T.B.H., Torensma, R., van Vliet, S.J., van Duijnhoven, G.C.F., Adema, G.J., van Kooyk, Y., Figdor, C.G., 2000c. Identification of DC-SIGN, a novel dendritic cellspecific ICAM-3 receptor that supports primary immune responses. Cell 100 575-585.

Gentry, M.K., Henchal, E.A., Mccown, J.M., Brandt, W.E., Dalrymple, J.M., 1982. Identification of distinct antigenic determinants on dengue-2 virus using monoclonal-antibodies. Am. J. Trop. Med. Hyg. 31, 548-555.

Guo, Y., Feinberg, H., Conroy, E., Mitchell, D.A., Alvarez, R., Blixt, O., Taylor, M.E., Weis, W.I. Drickamer, K., 2004. Structural basis for distinct ligand-binding and targeting properties of the receptors DC-SIGN and DC-SIGNR. Nat. Struct. Mol. Biol.11, 591-598.

Halary, F., Amara, A., Lortat-Jacob, H., Messerle, M., Delaunay, T., Houles, C., Fieschi, F., Arenzana-Seisdedos, F., Moreau, J.F., Dechanet-Merville, J., 2002. Human cytomegalovirus binding to DC-SIGN is required for dendritic cell infection and target cel trans-infection. Immunity 17, 653-664.

Halstead, S.B., 2007. Dengue. Lancet 370, 1644-1652.

Hatse, S., Princen, K., Gerlach, L.O., Bridger, G., Henson, G., De Clercq, E., Schwartz, T.W. Schols, D., 2001. Mutation of Asp(171) and Asp(262) of the chemokine receptor CXCR4 impairs its coreceptor function for human immunodeficiency virus-1 entry and abrogates the antagonistic activity of AMD3100. Mol. Pharmacol. 60, 164-173.

Henchal, E.A., Gentry, M.K., Mccown, J.M., Brandt, W.E., 1982. Dengue virus-specific and flavivirus group determinants identified with monoclonal-antibodies by indirect immunofluorescence. Am. J. Trop. Med. Hyg. 31, 830-836.

Hiramatsu, K., Tadano, M., Men, R., Lai, C.J., 1996. Mutational analysis of a neutralization epitope on the dengue type 2 virus (DEN2) envelope protein: monoclonal antibody resistant DEN2/DEN4 chimeras exhibit reduced mouse neurovirulence. Virology $224,437-445$.

Irie, K., Mohan, P.M., Sasaguri, Y., Putnak, R., Padmanabhan, R., 1989. Sequence-analysis of cloned dengue virus type-2 genome (New-guinea-C strain). Gene 75, 197-211.

Kou, Z., Quinn, M., Chen, H.Y., Rodrigo, W.W.S.I., Rose, R.C., Schlesinger, J.J., Jin, X., 2008 Monocytes, but not T or B cells, are the principal target cells for dengue virus (DV) infection among human peripheral blood mononuclear cells. J. Med. Virol. 80,134-146.

Lai, W.K., Sun, P.J., Zhang, J., Jennings, A., Lalor, P.F., Hubscher, S., McKeating, J.A., Adams, D.H., 2006. Expression of DC-SIGN and DC-SIGNR on human sinusoidal endothelium - a role for capturing hepatitis C virus particles. Am. J. Pathol. 169, 200-208.

Lozach, P.Y., Burleigh, L., Staropoli, I., Navarro-Sanchez, E., Harriague, J., Virelizier, J.L., Rey, F.A., Despres, P., Arenzana-Seisdedos, F., Amara, A., 2005. Dendritic cell-specific intercellular adhesion molecule 3-grabbing non-integrin (DC-SIGN)-mediated enhancement of dengue virus infection is independent of DC-SIGN internalization signals. J. Biol. Chem. 280, 23698-23708

Mairuhu, A.T.A., Wagenaar, J., Brandjes, D.P.M., van Gorp, E.C.M., 2004. Dengue: an arthropod-borne disease of global importance. Eur. J. Clin. Microbiol. Infect. Dis. 23 425-433.
Matrosovich, M., Matrosovich, T., Garten, W. Klenk, H.D., 2006. New low-viscosity overlay medium for viral plaque assays. Virol. J. 3.

Miller, J.L., Dewet, B.J.M., Martinez-Pomares, L., Radcliffe, C.M., Dwek, R.A., Rudd, P.M., Gordon, S., 2008. The mannose receptor mediates dengue virus infection of macrophages. Plos Pathogens. 4, e17.

Mitchell, D.A., Fadden, A.J., Drickamer, K., 2001. A novel mechanism of carbohydrate recognition by the C-type lectins DC-SIGN and DC-SIGNR - subunit organization and binding to multivalent ligands. J. Biol. Chem. 276, 28939-28945.

Mondotte, J.A., Lozach, P.Y., Amara, A., Gamarnik, A.V., 2007. Essential role of dengue virus envelope protein $\mathrm{N}$-glycosylation at asparagine-67 during viral propagation. J. Virol. 81, 7136-7148.

Navarro-Sanchez, E., Altmeyer, R., Amara, A., Schwartz, O., Fieschi, F., Virelizier, J.L., Arenzana-Seisdedos, F., Despres, P., 2003. Dendritic-cell-specific ICAM3-grabbing non-integrin is essential for the productive infection of human dendritic cells by mosquito-cell-derived dengue viruses. EMBO Rep. 4, 723-728.

Pöhlmann, S., Baribaud, F., Lee, B., Leslie, G.J., Sanchez, M.D., Hiebenthal-Millow, K., Munch, J., Kirchhoff, F., Doms, R.W., 2001. DC-SIGN interactions with human immunodeficiency virus type 1 and 2 and simian immunodeficiency virus. J. Virol. $75,4664-4672$.

Pokidysheva, E., Zhang, Y., Battisti, A.J., Bator-Kelly, C.M., Chipman, P.R., Xiao, C.A., Gregorio, G.G., Hendrickson, W.A., Kuhn, R.J., Rossmann, M.G., 2006. Cryo-EM reconstruction of dengue virus in complex with the carbohydrate recognition domain of DC-SIGN. Cell 124, 485-493.

Pollicita, M., Schols, D., Aquaro, S., Peumans, W.J., Van Damme, E.J.M., Perno, C.F., Balzarini, J., 2008. Carbohydrate-binding agents (CBAs) inhibit HIV-1 infection in human primary monocyte-derived macrophages (MDMs) and efficiently prevent MDM-directed viral capture and subsequent transmission to CD4(+) T lymphocytes. Virology 370, 382-391.

Schul, W., Liu, W., Xu, H.Y., Flamand, M., Vasudevan, S.G., 2007. A dengue fever viremia model in mice shows reduction in viral replication and suppression of the inflammatory response after treatment with antiviral drugs. J. Infect. Dis. 195, 665-674.

Soilleux, E.J., Morris, L.S., Leslie, G., Chehimi, J., Luo, Q., Levroney, E., Trowsdale, J., Montaner, L.J., Doms, R.W., Weissman, D., Coleman, N., Lee, B., 2002. Constitutive and induced expression of DC-SIGN on dendritic cell and macrophage subpopulations in situ and in vitro. J. Leukoc. Biol. 71, 445-457.

Tassaneetrithep, B., Burgess, T.H., Granelli-Piperno, A., Trumpfherer, C., Finke, J., Sun, W., Eller, M.A., Pattanapanyasat, K., Sarasombath, S., Birx, D.L., Steinman, R.M., Schlesinger, S., Marovich, M.A., 2003. DC-SIGN (CD209) mediates dengue virus infection of human dendritic cells. J. Exp. Med. 197, 823-829.

Turville, S.G., Vermeire, K., Balzarini, J., Schols, D., 2005. Sugar-binding proteins potently inhibit dendritic cell human immunodeficiency virus type 1 (HIV-1) infection and dendritic-cell-directed HIV-1 transfer. J. Virol. 79, 13519-13527.

Van Damme, E., Allen, A., Peumans, W., 1987. Isolation and characterization of a lectin with exclusive specificity towards mannose from snowdrop (Galanthus nivalis) bulbs. FEBS Lett. 251, 140-144.

Van Damme, E., Allen, A., Peumans, W., 1988. Related mannose-specific lectins from different species of the family Amaryllidaceae. Plant Physiol. 73, 52-57.

Van Damme, E., Kaku, H., Perini, F., Goldstein, I., Peeters, B., Yagi, F., Decock, B., Peumans, W., 1991. Biosynthesis, primary structure and molecular cloning of snowdrop (Galanthus nivalis L.) lectin. FEBS Lett. 202, 23-30.

van Kooyk, Y., Geijtenbeek, T.B.H., 2003. DC-SIGN: escape mechanism for pathogens. Nat. Rev., Immunol. 3, 697-709.

von Sydow, F.F.O., Santiago, M.A., Neves-Souza, P.C., Cerqueira, D.I.S., Gouvea, A.S., Lavatori, M.F.H., Bertho, A.L., Kubelka, C.F., 2000. Comparison of dengue infection in human mononuclear leukocytes with mosquito C6/36 and mammalian vero cells using flow cytometry to detect virus antigen. Mem. Inst. Oswaldo Cruz 95, 483-489.

Wu, S.J.L., Grouard-Vogel, G., Sun, W., Mascola, J.R., Brachtel, E., Putvatana, R., Louder, M.K., Filgueira, L., Marovich, M.A., Wong, H.K., Blauvelt, A., Murphy, G.S., Robb, M.L., Innes, B.L., Birx, D.L., Hayes, C.G., Frankel, S.S., 2000. Human skin Langerhans cells are targets of dengue virus infection. Nat. Med. 6, 816-820.

Wu, L., Martin, T.D., Vazeux, R., Unutmaz, D., KewalRamani, V.N., 2002. Functional evaluation of DC-SIGN monoclonal antibodies reveals DC-SIGN interactions with ICAM-3 do not promote human immunodeficiency virus type 1 transmission. J. Virol. 76, 5905-5914. 